\title{
Consumo de energia elétrica e produção de alface hidropônica com três intervalos entre irrigações
}

\author{
Consumption of electric energy and production of hydroponic lettuce under three irrigation intervals
}

\author{
Gean Lopes da Luz ${ }^{\mathrm{I}}$ Sandro Luís Petter Medeiros ${ }^{\mathrm{I}}$ Paulo Augusto Manfron ${ }^{\mathrm{I}}$ Elis Borcioni ${ }^{\mathrm{I}}$ \\ Liziany Müller ${ }^{\mathrm{I}}$ Alan Dischkaln do Amaral' ${ }^{\mathrm{I}}$ Katiule Pereira Morais ${ }^{\mathrm{I}}$
}

\begin{abstract}
Com o objetivo de avaliar a ação do regime de irrigação na produção da alface cv. "Regina” em sistema hidropônico NFT, foi conduzido um experimento no Departamento de Fitotecnia da Universidade Federal de Santa Maria, de maio a junho (outono) de 2005. Os tratamentos constituíram-se de três diferentes intervalos entre irrigações; $15 \mathrm{~min}$, 30min e 45min a cada irrigação de 15min. O delineamento experimental foi o de blocos ao acaso com três repetições. Foram realizadas as medidas fenométricas área foliar, fitomassa seca da parte aérea e fitomassa seca total, no momento do transplante e aos seis, nove, 16, 20 e 23 dias após o transplante. Não houve diferença significativa entre as variáveis fenométricas. $O$ intervalo de 45 min entre irrigações destacou-se por ter proporcionado diminuição no custo da energia elétrica de 42,1\%, sem prejuízos à produtividade.
\end{abstract}

Palavras-chave: Lactuca sativa L., produtividade, variáveis fenométricas, energia elétrica.

\section{ABSTRACT}

The objective of this study was to evaluate irrigation intervals on the production of lettuce, $\mathrm{cv}$. Regina, in an NFT hydroponic system. An experiment was carried out at the Crop Science Department, Federal University of Santa Maria, from May to June 2005. Treatments were three irrigation intervals (15min, 30min, and 45min) after a 15 minutes irrigation. The experimental design was a complete randomized block design with three replications. Leaf area, and above ground and total dry matter were measured at transplanting, and at 6, 9, 16, 20 and 23 days after transplanting. The treatment 45 minutes interval between successive irrigations allowed a 42,1\% saving electric energy without decreasing lettuce yeld.
Key words: Lactuca sativa L., yield, growth variables, electric energy.

De modo geral, a escolha das freqüências de irrigações no sistema hidropônico depende das características ambientais, especialmente da intensidade luminosa e da temperatura do ar, do meio de cultivo e da fisiologia da planta (ANDRIOLO, 1999).

A alface é uma hortaliça exigente em água, sendo que a quantidade e qualidade da mesma influem na produtividade da planta (DANTAS, 1997). Quando submetida a condições de déficit hídrico, ocorre aumento na temperatura das folhas e fechamento dos estômatos, diminuindo assim a fotossíntese. Como conseqüência, a cultura ajusta a superfície foliar à disponibilidade hídrica, o que provoca diminuição no rendimento (TAIZ \& ZEIGER, 1998).

$\mathrm{O}$ alto custo do sistema hidropônico tem estimulado a condução de novas pesquisas, especialmente a fim de reduzir os custos variáveis do sistema. Gastos com energia elétrica e solução nutritiva podem chegar a $42 \%$ do total dos custos variáveis (CARRASCO et al., 1999). AITA \& LONDERO (2000) estimaram o custo da energia elétrica e da solução nutritiva em 19,7 e 9,2\% do custo variável total, respectivamente. $\mathrm{O}$ aumento do preço desse insumo tem sido um fator negativo para a expansão da hidroponia, visto que o sistema de irrigação é

IDepartamento de Fitotecnia, Universidade Federal de Santa Maria (UFSM), 97105-900, Santa Maria, RS, Brasil. E-mail: geanluz@hotmail.com.*Autor para correspondência. 
dependente da eletricidade. Existe também, atualmente, uma grande preocupação com o desperdício de energia elétrica, sendo amplamente difundida em campanhas nacionais realizadas pela ELETROBRÁS. Este trabalho, portanto, tem importância social e ambiental no combate a esse desperdício.

O presente trabalho teve por objetivo avaliar a influência de diferentes intervalos entre irrigações na produção de alface em sistema hidropônico e verificar a economia de energia elétrica com o aumento desses intervalos.

O experimento foi conduzido em estufa plástica, na área experimental do Núcleo de Pesquisa em Ecofisiologia e Hidroponia (NUPECH), no Departamento de Fitotecnia da Universidade Federal de Santa Maria, RS, de 25 de maio a 17 de junho de 2005, utilizando-se a cultivar de alface “Regina”. Foram instalados três sistemas hidropônicos NFT (técnica do fluxo laminar de nutrientes) independentes, com um conjunto moto-bomba de 0,5 HP e duas bancadas de produção cada. As bancadas, dispostas no sentido norte-sul, constituíram-se por oito perfis hidropônicos cada, espaçados de 0,20m, com 23 plantas por perfil, espaçadas de $0,25 \mathrm{~m}$ (totalizando 368 plantas nas duas bancadas de cada sistema). Utilizou-se a solução nutritiva recomendada por CASTELLANE \& ARAÚJO (1995), monitorada a cada 48h, com a reposição de água quando necessário e com medidas da condutividade elétrica (CE) para reposição de 50\% dos nutrientes quando esta atingia $50 \%$ da CE inicial. Com o mesmo intervalo das medidas de CE, realizou-se o ajuste do $\mathrm{pH}$ da solução, de modo que este se mantivesse na faixa de 5,8 a 6,2 .

O delineamento experimental utilizado foi o de blocos ao acaso com três tratamentos (intervalos entre irrigações) e três repetições (blocos). Cada bloco, com área útil de $4,2 \mathrm{~m}^{2}$, era formado por 84 plantas. Os tratamentos constituíram-se de três diferentes intervalos entre irrigações a cada irrigação de 15 minutos (T15 - intervalos de 15min, T30 - intervalos de 30min e T45 - intervalos de 45min) das 6h às $19 \mathrm{~h}$. Durante o período noturno (das $19 \mathrm{~h}$ às $6 \mathrm{~h}$ ), houve irrigação de 15 minutos, a cada duas horas, em todos os tratamentos. Os tratamentos foram aplicados um dia após o transplante. As irrigações foram controladas por programador horário-eletromecânico, instalado em cada sistema.

Com um medidor de energia elétrica instalado em um dos sistemas (T15), obteve-se o consumo de energia elétrica, o qual, a partir do conhecimento do tempo de funcionamento diário da moto-bomba em cada tratamento, foi extrapolado de forma proporcional para os demais sistemas. Os valores de temperatura do ar foram obtidos de um termógrafo instalado no centro da estufa, a $1,5 \mathrm{~m}$ do solo.

As medidas fenométricas realizadas foram área foliar (AF), fitomassa seca total (FST), fitomassa seca da parte aérea (FSPA) e fitomassa seca do sistema radicular (FSR), em amostras de três plantas por bloco, totalizando nove plantas por tratamento. A área foliar foi obtida pelo método de discos, que consiste na retirada de discos do limbo foliar, com área conhecida, e a partir da relação da massa seca de discos com a massa seca de folhas, conserva-se a mesma proporção para, com o conhecimento da área dos discos, determinar-se a área das folhas. Para a obtenção da fitomassa seca das partes da planta (folhas, discos, caule e raízes), o material foi acondicionado em sacos de papel individualizados e identificados, colocados em estufa de secagem de ventilação forçada a $65^{\circ} \mathrm{C}$, até peso constante. As medidas fenométricas foram realizadas no momento do transplante e aos seis, nove, 16, 20 e 23 dias após o transplante (DAT).

Os resultados foram submetidos à análise de variância e as médias comparadas pelo teste de Tukey a 5\% de probabilidade de erro.

Os valores de AF, FST e FSPA, nos intervalos T15, T30 e T45, não diferiram significativamente entre si (Tabela 1 ). Os valores médios obtidos nos três tratamentos para as variáveis foram de $2999,88 \mathrm{~cm}^{2}, 7,40 \mathrm{~g}$ e 6,52g, respectivamente. Esses resultados são similares aos verificados por BACKES et al. (2003) e CARON et al. (2003), que, respectivamente, durante a primavera e o outono, avaliaram a produção de fitomassa da alface hidropônica e destacaram a cultivar "Regina”, com FST de 9,7g planta $^{-1}$ e 7,1g planta $^{-1}$, respectivamente.

Durante o período de cultivo, a temperatura média do ar foi de $24^{\circ} \mathrm{C}$, a temperatura mínima média foi de $19^{\circ} \mathrm{C}$ e a temperatura máxima média foi de $29^{\circ} \mathrm{C}$. CERMEÑO (1977) cita como valores de temperatura máxima e mínima do ar para o crescimento da alface $30^{\circ} \mathrm{C}$ e $6^{\circ} \mathrm{C}$, respectivamente. Portanto, para esse experimento, as temperaturas médias permaneceram dentro dos limites para o bom crescimento da cultura.

O aumento do intervalo entre irrigações não prejudicou a produção de fitomassa das plantas de alface, possivelmente pelo fato de as plantas submetidas à menor disponibilidade hídrica apresentarem maior crescimento do sistema radicular (Tabela 1), o que provavelmente promoveu maior retenção da solução nutritiva, permitindo a disponibilidade de água e nutrientes para as plantas por um período maior que os $15 \mathrm{~min}$ de intervalo comumente aplicados em cultivos comerciais. Portanto, o aumento da retenção da solução nutritiva decorrente do acréscimo da massa e do volume radicular evitou, 
Tabela 1 - Área foliar (AF), fitomassa seca total (FST), fitomassa seca de parte aérea (FSPA) e fitomassa seca do sistema radicular (FSR) de plantas de alface durante o ciclo de cultivo (dias após o transplante - DAT) para os intervalos entre irrigações 15 min (T15), 30 min (T30) e 45 min (T45). UFSM, Santa Maria - RS, 2005.

\begin{tabular}{|c|c|c|c|c|c|c|}
\hline \multirow[t]{2}{*}{ Tratamento } & \multicolumn{6}{|c|}{ Época de avaliação } \\
\hline & Transplante & 06 DAT & 09 DAT & 16 DAT & 20 DAT & 23 DAT \\
\hline & \multicolumn{2}{|c|}{------------------------------ } & \multicolumn{2}{|c|}{$\mathrm{AF}\left(\mathrm{cm}^{2}\right)$} & \multicolumn{2}{|c|}{ 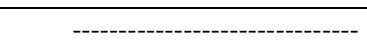 } \\
\hline T15 & $178,8 \mathrm{a}$ & $461,9 a$ & 536,3a & $2336,2^{\mathrm{a}}$ & 2314,6a & $2900,6 a$ \\
\hline T30 & $167,6 a$ & $572,7 \mathrm{a}$ & $668,7 a$ & $2470,5^{a}$ & $2262,4 a$ & $2869,5 \mathrm{a}$ \\
\hline T45 & $203,7 a$ & $391,1 \mathrm{a}$ & $636,1 \mathrm{a}$ & $2005,9^{\mathrm{a}}$ & $2655,5 a$ & $3229,6 a$ \\
\hline CV (\%) & 13,0 & 23,3 & \multicolumn{2}{|c|}{21,5} & 12,6 & 15,4 \\
\hline T15 & $0,56 a$ & 1,37a & FST (g) & $5,77^{\mathrm{a}}$ & 6,34a & 7,10a \\
\hline Т30 & $0,56 a$ & $1,62 \mathrm{a}$ & $2,27 \mathrm{a}$ & 5,83a & 6,093a & $6,91 \mathrm{a}$ \\
\hline T45 & $0,55 a$ & $1,20 \mathrm{a}$ & $1,82 \mathrm{a}$ & $5,40 \mathrm{a}$ & $6,86 a$ & $8,20 \mathrm{a}$ \\
\hline \multirow[t]{2}{*}{ CV (\%) } & 14,10 & 24,04 & 19,93 & 18,83 & 16,85 & 13,00 \\
\hline & ---- & ------ & \multicolumn{2}{|c|}{ FSPA (g) } & $\cdots$ & ------ \\
\hline $\mathrm{T} 15$ & $0,29 a$ & $1,04 a$ & $1,73 a$ & 5,13a & $5,56 a$ & 6,33a \\
\hline T30 & $0,27 a$ & $1,29 a$ & $1,86 a$ & $5,37 a$ & $5,42 \mathrm{a}$ & $6,21 \mathrm{a}$ \\
\hline T45 & 0,33a & 0,93a & 1,53a & $4,80 \mathrm{a}$ & $6,05 a$ & $7,01 \mathrm{a}$ \\
\hline \multirow[t]{2}{*}{ CV (\%) } & 13,05 & 25,47 & 20,40 & 20,26 & 16,57 & 13,34 \\
\hline & & & \multicolumn{2}{|c|}{ FSR (g) } & & \\
\hline T15 & $0,17 a$ & $0,33 a$ & $0,36 a$ & $0,64 a$ & $0,73 \mathrm{~b}$ & $0,76 b$ \\
\hline Т30 & $0,17 \mathrm{a}$ & $0,33 a$ & $0,41 \mathrm{a}$ & $0,67 a$ & $0,74 a b$ & $0,83 a b$ \\
\hline T45 & $0,14 a$ & $0,27 a$ & $0,29 a$ & $0,63 a$ & $0,84 a$ & 0,91a \\
\hline CV (\%) & 13,05 & 25,48 & 20,41 & 20,26 & 16,57 & 13,34 \\
\hline
\end{tabular}

*As médias não seguidas por mesma letra diferem significativamente entre si, na coluna, pelo teste TUKEY a 5\% de probabilidade de erro.

aos tratamentos de maior intervalo (T30 e T45), um possível déficit hídrico significativo para a cultura.

O tempo de funcionamento do conjunto moto-bomba para T15 foi de $465 \mathrm{~min} \mathrm{dia}^{-1}$, para T30 de $375 \mathrm{~min}$ dia $^{-1}$ e para T45 foi de $270 \mathrm{~min} \mathrm{dia}^{-1}$, sendo, a partir disso, possível avaliar-se o consumo de energia dos intervalos entre irrigações. Ocorreu decréscimo no consumo de energia elétrica pelo conjunto moto-bomba, conforme o aumento do intervalo entre irrigações (Tabela 2), sendo que esta diferença, ao longo de vários ciclos de cultivo, pode tornar-se bastante vantajosa, diminuindo os custos de produção da cultura e o desperdício de energia elétrica.
Em síntese, não houve diferença entre os tratamentos para as variáveis analisadas nas condições de outono, na região de Santa Maria, RS. Entretanto, o intervalo T45 apresentou-se mais vantajoso por, nas condições do presente trabalho, proporcionar menor consumo de energia elétrica (42,1\%), representando conveniente economia em cultivos sucessivos.

\section{AGRADECIMENTOS}

Ao Conselho Nacional de Desenvolvimento Científico e Tecnológico (CNPq) e à Coordenação de Aperfeiçoamento de Pessoal de Nível Superior (CAPES), pelas

Tabela 2 - Valores de consumo diário (CDEE), consumo total (CTEE), custo diário (Cust DEE), custo total (Cust TEE) de energia elétrica por sistema de cultivo e custo de energia elétrica por planta de alface (Cust EE/PL) em sistema hidropônico (NFT) submetido a três intervalos entre irrigações: 15 min (T15), 30 min (T30) e 45 min (T45). UFSM, Santa Maria, RS, 2005.

\begin{tabular}{lccccc}
\hline & CDEE & CTEE* & Cust DEE & \multicolumn{2}{c}{ Cust TEE* } \\
Intervalos entre irrigações & KWh & KWh & R\$ dia ${ }^{-1}$ & R\$ & R\$ \\
\hline T15 & 2,89 & 69,36 & 1,30 & 31,10 & 24,06 \\
T30 & 2,33 & 55,92 & 1,04 & 0,07 \\
T45 & 1,67 & 40,08 & 0,75 & 18,00 \\
\hline
\end{tabular}

* Valores acumulados nos 23 dias de cultivo para duas bancadas (368 plantas). 
bolsas de iniciação científica, mestrado e doutorado concedidas, bem como ao CNPq, pela Bolsa de Produtividade em Pesquisa.

\section{REFERÊNCIAS}

AITA, A.; LONDERO, F.A.A. Custo de produção de alface hidropônica. In: SANTOS, O. (Ed.). Hidroponia da alface. Santa Maria: UFSM/ Pró-reitoria de Extensão, 2000. 160p. p.142-144.

ANDRIOLO, J.L. Fisiologia das culturas protegidas. Santa Maria: UFSM, 1999. 142p.

BACKES, F.A.A.L.; CARON, B.O.et al. Influência da temperatura do ar e da radiação solar no acúmulo de fitomassa da alface. Revista Brasileira de Agrometeorologia, v.11, n.2, p.275-283, 2003.
CARRASCO, G. et al. Development of nutrient film technique "NFT" in Chile: The use of intermittent recirculation regimes. Acta horticulturae, v.481, p.305-309, 1999.

CASTELlane, P.D.; ARAUJO, J.A.C. Cultivo sem solohidroponia. Jaboticabal: FUNEP, 1995. 43p.

CERMEÑO, Z.S. Cultivo de plantas hortícolas em estufa. Lisboa: Litexa, 1977. 368p.

DANTAS, R.T. Parâmetros agrometeorológicos e análise de crescimento de alface (Lactuca sativa $\mathrm{L}$.) em ambientes natural e protegido. 1997. 109f. Tese (Doutorado em Agronomia) - UNESP, Botucatu.

TAIZ, L.; ZEIGER, E. Plant physiology. California: The Benjamin/Cummigs, 1998. 559p. 